\title{
The development of creative competence of primary school students under the condition of inclusive education
}

\author{
Alexey Dmitriev ${ }^{1, *}$, Valeriya Chukalskaya ${ }^{2}$,Svetlana Dmitrieva ${ }^{1}$, Slavica Golubović ${ }^{1,2}$, \\ Evgeniya Novosiltseva ${ }^{1}$ \\ ${ }^{1}$ Moscow Region State University, 10A, Radio str, 105005,Moscow, Russia \\ ${ }^{2}$ University of Belgrade, 1, Studentski trg, 11000, Belgrade, Serbia
}

\begin{abstract}
The importance of formation and development of creativity of primary school students is recognized by specialists in pedagogy and psychology. At the same time, one of the topical problems is the increase in the number of children with special educational needs. The purpose of the study is to regard the function of the aesthetic and imaginative perception of the world as a constituent of creative competence of primary school students in the context of a potential growth point for a child with specific learning disabilities. The subject of the study is the dynamics of indicators of creative competence (creative imagination, in particular) demonstrated by children as a result of mastering an integrated set of activities aimed to develop creative thinking in primary school students to be able to solve tasks, as well as to form creative competence, to improve self-expression and self-regulation through the use of tools of creative activities and to introduce children to works of culture and art in the conditions of inclusive education. At the stage of the ascertaining experiment, the creative imagination of children participating in the experiment was evaluated according to the methodologies of Dyachenko O. ("Drawing figures") and Kravtsova E. ("Where is its place?"). The general tendency, which is true for the results of the ascertaining experiment with the application of both methods, is the absence of children with a high level of imagination development in the group studied. Integrated lessons aimed to the formation and development of creative imagination in children with developmental delay were carried out for a year and a half, in inclusive groups. In the course of the complex work, the elements of art therapy, logopedic rhythm, psycho-gymnastics, fairy-tale therapy, dance movement therapy and music therapy were used, the means of theatricalization and dramatization were actively applied. According to the results of the ascertaining experiment, it is revealed that the subjects have the ability to overcome the stereotypes formed on the basis of the accumulated experience, which is one of the elements that determine the success of creative activity. As a result of the study, it was discovered that creative imagination regarded as a component of the creative competence of primary school students could be stimulated and improved with the help of a psychological-pedagogical influence during the application of the methodology of integrated lessons of the aesthetic course.
\end{abstract}

* Corresponding author: 7828262@inbox.ru 


\section{Introduction}

The importance of the formation and development of creativity in the process of personal development of children is universally recognized by scientists in the field of pedagogy and psychology [3, 7]. However, the environment of modern children's development is qualitatively different from the traditional environment of cultural-creative thinking in Russia of the 20th century, which is formed by various models of education, folklore works, active and role-playing games that accompanied a person throughout the childhood. Nowadays, the majority of pupils have an undeveloped creative thinking, the work of children's imagination is suppressed by the variety of ready-made stereotypical images present in abundance both in the entertainment sphere and in the daily life of the child. The development of the entertainment industry provokes the disappearance of the external incentives for children to be creative, to create new images, to fantasize [20].

Furthermore, a creative approach to the solution of the problems of professional activity in adulthood is a particularly valuable advantage at the present time. The ability to flexibly apply their own competencies in the process of the solution of tasks presented by a changing external environment becomes a necessity for successful professional performance.

Therefore, it becomes relevant to search for such forms and methods of psychologicalpedagogical work that would allow students to form and develop the creative skills and thinking. The ideology of complex imaginative and aesthetic development provides a wide range of opportunities for the activity of a psychologist teacher in this area.

The problems of imaginative and aesthetic education of children are reflected in the studies of Zatsepina M.B., Zuikova E.N., Komarova T.S., Labunskaya G.V., Penya T.G., Chumicheva R.M., Yusova B.P., and others. The researchers came to the conclusion that the application of a set of techniques and methods of aesthetic development in the educational process leads to the formation of students's creative beginnings in the activity: children display enthusiasm, independence and initiative during the usage of familiar working methods to the new content, they find new ways to solve the tasks, express their feelings emotionally by verbal methods, as well as by various visual means.

In recent times, the number of children in need of a specialized care, children with disabilities, has increased significantly. In order to solve this problem, children's centers, logopedic and psychological rooms are being established at schools, kindergartens, and clinics. However, the issue of application of aesthetic and imaginative classes aimed to form and develop creativity and creative potential of children with special educational needs in the corrective courses of development is insufficiently developed. In addition, the aesthetic and imaginative perception of the world could become a potential growth point for a child with specific learning disorders. The development of creative competence by means of aesthetic education prevents the occurrence of a failure, as well as a sense of frustration that could occur within the social and educational context and form an image of a child's own inability and inadequacy. In this regard, the development of creative abilities of students with special educational needs receives a new stimulus.

Over the extended period of time, many specialists have addressed the problem of imagination development of children with special educational needs. However, despite the great contribution of national scientists to the study of the creative imagination of this category of children (Agavelyan M.G., Vygotsky L.S., Zabramnaya S.D., Isaev D.N., Lubovsky V.I., Petrov V.G., Rubinshtein S.Ya., and others), many issues relating to the research of the distinctive features, mechanisms and conditions of its development remain insufficiently studied.

In the studies of national and international scientists (Vygotsky L.S., Zaporozhets A.V., Ilyin E.P., Kosheleva A.D., Leontiev A.N., Neverovich Ya.Z., Casey, Harris, Saami, and 
others) it is noted that the level of creative imagination development is an important component of emotional development, which is recognized as one of the major factors in the adaptation and socialization of children.

The formation of creative competence of students with developmental disorders through the development of their creative imagination function could have a positive effect on the development of creative thinking during the solution of various problems, as well as on the establishment of social rapports of this category of students and on the meaningful interpersonal interaction. In addition, it would effectively influence them to master their school curriculum, and improve the quality of life in the future.

Vygotsky L.S. [3] pointed out the consistent patterns in the development of normal and abnormal children. The abnormal development could be balanced with the support of the possibility of interpersonal interaction with peers under the pedagogical accompaniment, based on the zone of proximal development. The influence of care and education is a leading factor in the formation of higher mental functions, which include imagination. In an complex approach to the development of a child with special health needs, the necessary element of the system is the compensation and development of imagination, creative perception and creative thinking, which form the basis of creative competence as a theoretical and practical readiness to act creatively in various life situations. This statement is the basis of the article.

The authors of the article proposed an integrated set of classes aimed to develop the ability of creative thinking of primary school students to solve various tasks, to form creative competence, to develop forms of self-expression and self-regulation through the tools of creative activity, as well as to introduce works of culture and art to children under inclusive education. During the preparatory work, the existing psychological and pedagogical methods and approaches to the development of children's creative imagination were analyzed. As a result of the analysis, the methods that comply with specific requirements of special pedagogy and psychology were selected, and an integrated plan of corrective development work on the formation of the creative competence of primary school students with special health needs (with a developmental delay diagnosis, in particular) within extracurricular activities in the inclusive groups was framed.

In the process of the implementation of an integrated organizational approach, it is considered to be of great importance to demonstrate the ability of art to express similar or contrasting thoughts, feelings, ideas and images to the students rather than to curiously alternate between the techniques based on various types of creative activity. Therefore, the personality and professional competence of a teacher who implements an integrated approach to the development of creative competence of students with special educational needs becomes crucial.

The methodology for the formation and development of creative competence of pupils in the conditions of inclusive learning, developed and implemented during the experiment, is based on the educational entertainment approach, since the process of development and expression of creative imagination in the course of a game is more effective than in any other types of activities. Diverse games included as an element of classes allow to comprehensively impact on the process of corrective assistance to children with special educational needs. Creative activities involved in the work on the child's development allows to modify the pedagogical work to a role-playing or didactic game.

The areas of corrective development work that are part of the methodology comprise art therapy, logopedic rhythm, psycho-gymnastics, fairy-tale therapy, dance movement therapy, music classes, as well as the means of theatricalization and dramatization.

The objectives that are accomplished in the process of psychological-pedagogical work with children within the framework of the methodology developed include:

- development of creative imagination, activation of imagination; 
- introduction to the means of creative expression;

- normalization of the process of self-regulation;

- communication skills development;

- development of motor skills, balance control, flexibility.

\section{Methods}

The implementation of the methodology of the formation and development of student's creative competence in the conditions of inclusive education was carried out on the basis of the children's center in Pushkino. In 2017-2018, weekly group classes were conducted according to the presented methodology. The inclusive groups consisted of 4-8 people, no more that $50 \%$ of which were children with special health needs. The age of the children at the moment of the start of the experiment ranged from 6 to 8 years. Most of the children with disabilities who participated in the experiment had combined symptoms with a prevalence of speech and communication disorders. Psychological passivity and emotional lability were also common. A significant specific problem that was peculiar to the majority of the children participating in the experiment was the problem of emotional-volitional disorders, accompanied by neuroticism, disinhibition of the nervous system, mood instability, increased emotional sensitivity, negativism, dependence and passivity in behavior, as well as inability to follow the rules. In order to improve and stabilize the psycho-emotional state of these children, the Center's specialists decided to experimentally include the artistic classes regarded as a constituent of the methodology, that implies an integrative approach, in the system of pedagogical correction.

The experimental work with children according to the methodology of creative imagination development was aimed to form the ability to recreate the images of familiar characters and phenomena with the use of artistic, literary, and musical-rhythmic means, to develop the ability to produce their own ideas, and to improve the interpersonal communication skills in the process of group creative work.

In order to assess the outcome of psychological-pedagogical work, the studies that were conducted within the framework of the proposed course of integrated classes allowed to determine the relevant level of creative imagination development. The methodology of Dyachenko O. ("Drawing figures" (1988)) [6] was chosen for the nonverbal assessment of the level of imagination development of students, while the methodology of Kravtsova E. ("Where is its place?" (2004)) [11] was selected for the verbally supported evaluation of the level of creative imagination development.

When conducting the research according to the "Drawing figures" methodology, a child was asked to draw ten geometric shapes in such sequence that various objects were depicted.

In order to analyze the outcome, the resulting objects were compared both within the work of each child and within the group. Duplicate objects were not taken into consideration. The original (repeated neither in the child's work, nor in the group) images of each child were counted. Thereafter, the coefficient of originality $\left(\mathrm{C}_{\mathrm{O}}\right)$, that is the arithmetic mean number of original images in the group, was calculated.

In the process of division of children into subgroups according to the level of imagination development, the obtained coefficient of originality $(+/-2$ points) was considered to be corresponding to the average level of imagination development of the participant of the experiment. With a downward deviation from the group average value by more than two points, the level of development of a child's imagination was assessed as low. With an upward deviation from the group average value by 2 or more points, the level of development of a child's imagination was assessed as high. 
When conducting the study according to the methodology of Kravtsova E., the researcher asked a child to put seven objects in unusual places and explain why these objects were located there. The author of the methodology recommends to consider a child to have a high level of imagination development (LID), if, in addition to placing the objects in non-standard places, the child gave a detailed description of the circumstances of the case. If a child placed images of the objects in unusual places but did not provide comments, or they were identical and not detailed, the level of imagination development was recognized as medium. In case of difficulties in completing the assignment, the inability of the child to avoid stereotypes when placing objects in the story picture, the level of imagination development was recognized as low.

\section{Results}

The results of the analysis of the level of creative imagination development before the start of the classes of the proposed program of integrated imaginative and aesthetic development are presented below. It should be noted that the examination of children with developmental delay was carried out according to the adapted methodology, that balances the influence of the childrens' lowered performance level and concentration difficulty on the result of the research [23]. The total number of children with developmental delay participated in the study was 53 people.

Table 1. The division of the group according to the LID discovered due to the results of ascertaining testing based on the "Drawing figures" methodology of Dyachenko O., the average coefficient of originality $=0.91$.

\begin{tabular}{|c|c|c|}
\hline $\begin{array}{c}\text { Level of imagination } \\
\text { development }\end{array}$ & Number of original images & Group size \\
\hline Low & 0 & 25 \\
\hline Medium & From 1 to 3 & 28 \\
\hline High & 3 and more & 0 \\
\hline Total: & 48 & 53 \\
\hline
\end{tabular}

According to the results of the experiment conducted on the basis of the "Drawing figures" methodology, 25 children demonstrated a low level of development, 28 children displayed a medium level. As a result of the testing carried out according to the "Where is its place?" methodology, 37 children showed a low level of imagination development, and 16 subjects demonstrated a medium LID. None of the children of the study group displayed a high LID.

The significant distinctions between the number of children who showed a low and medium LID in the process of testing that was based on different methods occurred due to the counting specificity. The average coefficient of originality in the "Drawing Figures" methodology is calculated according to the formula $\mathrm{CO}=\left(\mathrm{I}_{1}+\mathrm{I}_{2}+\ldots \mathrm{I}_{\mathrm{n}}\right) / \mathrm{n}$, where $\mathrm{I}$ denotes the number of original (non-repeated) images presented by each of the children participating in the experiment, and $\mathrm{n}$ is the group size. A child is classified into a group by the LID on the basis of a comparison of the child's personal I (the number of original images presented) and the average $\mathrm{CO}$ in the group. The $\mathrm{CO}$ value $+/-2$ is assumed to correspond to the average LID. The group with a low level of imagination comprise the children who presented fewer original images than the $\mathrm{CO}$ by 2 or more. Thus, the obtained structure of the group according to the LID is relative and depends on the average group CO. In contrast, the "Where is its place?" methodology provides an absolute assessment based on the "completed/failed to complete" characteristic. 


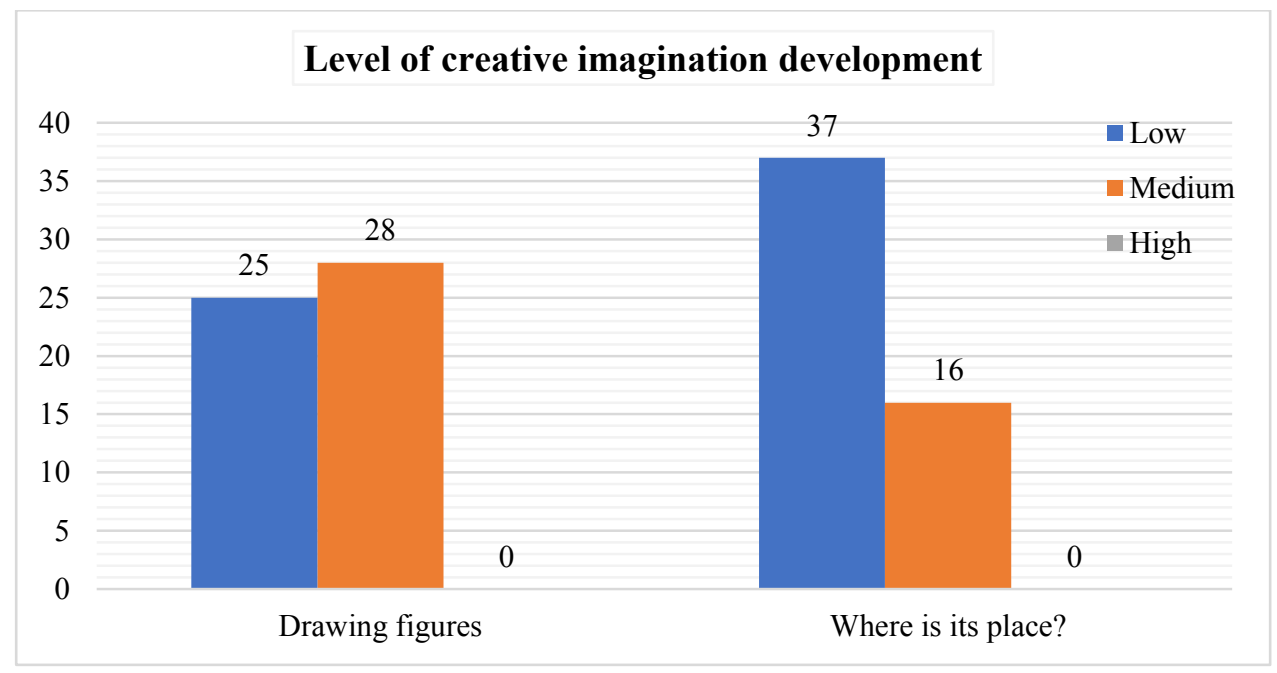

Fig. 1. "Level of creative imagination development" diagram, the ascertaining experiment; number of people.

The general tendency that is valid for the results of the experiment by both methods is the absence of children with a high level of imagination in the study group. The "Drawing figures" methodology revealed a final ratio of the low LID to the medium level which was $25: 28$ or $47.17 \%$ of children did not present a single original image during the study, and $52.83 \%$ of children displayed 1 or 2 original images during the testing. In the process of assessment of the level of creative imagination development by the "Where is its place?" methodology the ratio of low to medium LID is $37: 16$ or $69.81 \%$ and $30.19 \%$ of the number of students in the study group, correspondingly.

The identical research was carried out after the completion of the children's course of integrated corrective and development classes of the imaginative and aesthetic nine-months long module.

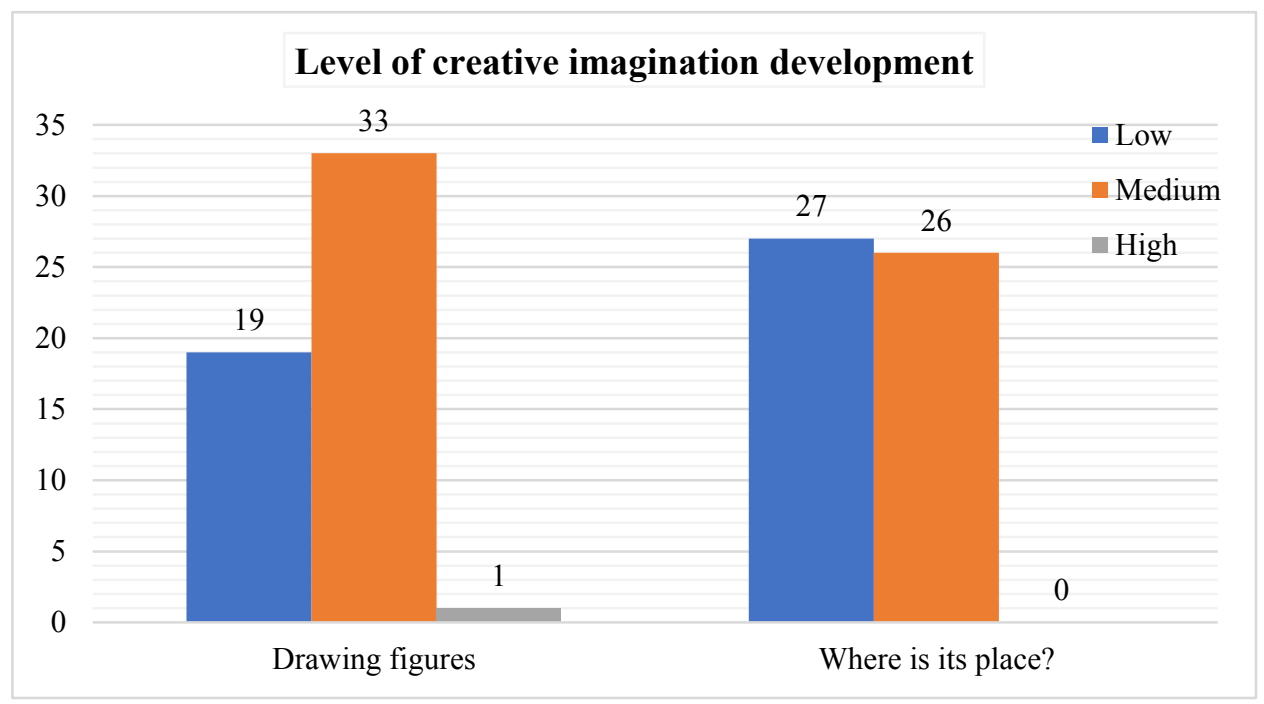

Fig. 2. "The level of creative imagination development" diagram, the control experiment; number of people. 


\section{Discussion}

The results obtained indicate an increase in the level of creative imagination of students. Thus, the results discovered by the "Where is whose place?" methodology of Kravtsova E. demonstrate that the number of children with a low level of imagination decreased by 10 people in the study group. Almost half of the subjects (26 out of 53 children or $49.06 \%$ ) successfully completed the test by placing objects in unusual places. The increase of the indicator presented by the subjects in the segment of the medium LID was $63.5 \%$. Furthermore, in the segment of low level of imagination, there is a decrease in the number from 37 to 27 children, or by $28.2 \%$. This result points out the formed ability of children to find a non-standard solution to the proposed problem. The ability described above is one of the elements that determine the success of creative activity.

The increase in the level of creative imagination development is observed according to the results of a research conducted according to the "Drawing figures" methodology of Dyachenko O. as well: the number of subjects who demonstrated a low level of imagination development decreased by 6 people $-35.85 \%$ in the control experiment in contrast to $47.17 \%$ in the ascertaining experiment. It was also noted that the average group coefficient of originality increased from 0.91 to 1.13 non-repeating images on average in the group.

\section{Conclusion}

The research conducted allows to state that creative imagination regarded as a component of the creative competence of primary school students could be stimulated and improved with the help of a psychological-pedagogical influence during the integrated classes of the aesthetic course carried out as part of extracurricular activities of children. Art-therapeutic and musical-rhythmic forms of work provide the teacher with a wide range of tools and methods of influence, allow to organize the effective interaction of students both among themselves and with the teacher, and are also emotionally attractive for children of different neurological states.

The development of creative competence as a necessary foundation for the comprehensive development of students is one of the key problems of the present education system, especially in the context of the increasing number of children with special educational needs.

The developed creative imagination not only allows students to successfully integrate into the conditions of modern society, but also helps to subjectively assess the state of their own emotional-volitional sphere which contributes to the adequate self-development in the future.

\section{References}

1. M.G. Agavelyan, Identification of nonverbal human behavior by mentally retarded schoolchildren: autoref. dis. (M., 1998)

2. N.Yu. Verhoturova, Study and evaluation of emotional and personal tendencies and behavioral repetitions of emotional response of primary school children with intellectual disabilities (Belgrade, medical Research center for special pedagogy and rehabilitation, 2019)

3. L.S. Vygotsky, Psychology of child development (M., Eksmo, 2004)

4. A.A. Dmitriev, World journal of applied Sciences 27 (education, Law, Economics, language and communication) (2013) 
5. A.A. Dmitriev, Life Science Journal 11(12s), 576 (2014)

6. M. Dyachenko, Development of the preschool child's imagination (M., International educational and psychological College, 1996)

7. A.V. Zaporozhets, Emotional development of a preschooler (Moscow, Enlightenment, 1985)

8. S.D. Zabramnaya, O.V. Borovik, Methodological recommendations for the manual "Practical material for conducting psychological and pedagogical examination of children". Manual for psychological and pedagogical commissions (M., Vlados, 2003)

9. P.L. Harris, Children and emotions. Development of psychological understanding (Oxford, England, Basil Blackweii, 1989)

10. S. Saarni, Emotional development: action, communication and understanding. Handbook of child psychology: social, emotional and personal development (New York, Wiley, 1998)

11. A.V. Zaporozhets, A.P. Usova, Touch education of preschool children (M., 1963)

12. A.D. Kosheleva, Emotional development of preschoolers (M., Akademiya, 2003)

13. E.E. Kravtsova, Wake up the wizard in the child: KN. for educators of children. garden and parents (M., Enlightenment: educational literature, 1996)

14. G.V. Labunskaya, Artistic education of children in the family (M., Pedagogy, 1970)

15. A.N. Leontiev, Needs, motives and emotions: abstract of lectures (M., MSU publishing house, 1971)

16. V.I. Lubovsky, Special psychology: studies. student's guide (Moscow, Akademiya, 2005)

17. T.G. Penya, Theater classes for younger school students (M., 2011)

18. V.G. Petrova, Psychology of mentally retarded schoolchildren (Moscow, Akademiya, 2002)

19. J. Raven, Competence in modern society: influence, development, and implementation (M., Kogito Center, 2002)

20. S.Y. Rubinshtein, Psychology of the mentally retarded schoolchild (M., Enlightenment, 1986)

21. S. Rubinstein, Fundamentals of General psychology (St. Petersburg, Peter, 2012)

22. I. Slobodchikov, E. Isaev, Fundamentals of psychological anthropology. Human psychology: an Introduction to the psychology of subjectivity (M., School Press, 1995)

23. O.N. Tverskaya, BAM-biology and medicine 3 (2015)

24. R.M. Chumicheva, Anthropological and pedagogical support of the child's life and development (Stavropol, service school, 2005)

25. V.I. Chukalskaya, Features of testing the level of development of creative imagination in primary school children with mental retardation, using the adapted method of $O$. Dyachenko "Drawing figures". Current issues of designing psychological and pedagogical technologies with children and adolescents with SEN (M., Moscow state University, 2019) 